\title{
Experimental Investigation of Visualization and Package of Phase Change Material for Thermal Management of 18650 Lithium-Ion Battery
}

\author{
Qingyu Wu \\ College of Automotive Engineering, Shanghai University of Engineering Science, Shanghai, China \\ Email: 1596222802@qq.com
}

How to cite this paper: Wu, Q.Y. (2018) Experimental Investigation of Visualization and Package of Phase Change Material for Thermal Management of 18650 Lithium-Ion Battery. Open Access Library Journal, 5: e5035.

https://doi.org/10.4236/oalib.1105035

Received: November 6, 2018

Accepted: November 23, 2018

Published: November 26, 2018

Copyright $\odot 2018$ by author and Open Access Library Inc.

This work is licensed under the Creative Commons Attribution International License (CC BY 4.0). http://creativecommons.org/licenses/by/4.0/

\begin{abstract}
The visualization of phase change process of phase change material (PCM) for thermal management of 18650 lithium-ion battery was studied by experimental method. The configuration consists of a semi-cylindrical battery allocated in the center of a semi-concentric housing made of aluminum, composite PCM and a transparent plate of $3 \mathrm{~mm}$ thick made of acrylics. The results show that the composite PCM/copper foam has better thermal performance. Moreover, the leakage problem can be solved by encapsulating composite PCM into closed bags made of aluminum plastic film.
\end{abstract}

\section{Subject Areas}

Electric Engineering, Mechanical Engineering

\section{Keywords}

Phase Change Material (PCM), Enhanced Heat Transfer, Phase Change Process, Visualization, Package

\section{Introduction}

The lithium-ion batteries are considered the most commercially feasible power sources for EVs/HEVs due to its high energy density, long life cycle, environmental friendliness and reasonable cost [1]. However, high temperature may affect the performance of battery including power and energy capacity, cycle life or even cause thermal runaway of the battery [2] [3]. Ramadass et al. [2] did a capacity fade analysis and elucidated that batteries lost more than $60 \%$ of initial capacity after 800 cycles at $50^{\circ} \mathrm{C}$ and $70 \%$ after 500 cycles at $55^{\circ} \mathrm{C}$. Ping et al. [3] pointed out that the overheating of the battery under elevated temperature can 
produce a large amount of heat due to exothermic reaction inside the battery, which eventually leads to the thermal runaway of the battery. In general, it has been widely recognized that the maximum temperature of the batteries and the temperature difference across the entire battery module should be maintained below the $50^{\circ} \mathrm{C}$ and the $5^{\circ} \mathrm{C}$, respectively [4] [5]. Therefore, it is necessary to develop thermal management method to maintain the battery within acceptable temperature range.

A latent heat thermal energy storage method based on phase change material (PCM) such as paraffin has raised increasing interests for thermal management of lithium-ion batteries. The solid-liquid phase change process of PCM is analyzed to investigate the thermal energy storage [6]. Thermal conductivity enhancement of PCM has been studied extensively over several decades to work out the problems of low thermal conductivity of PCM by adding highly conductive materials such as fins [7], expanded graphite [8] and metal foams [6] [9]. Wang et al. [7] did an analysis of the thermal behavior of a composite paraffin and fin structure. Their results showed that the battery temperature for the finned cases were lower than that for the pure PCM case, indicating that adding fins improved the thermal performance of battery. The new phase change composites using erythritol as a PCM and graphite and nickel particles as highly thermal conductive fillers was developed by Teppi et al. [8]. And the effective thermal conductivities of phase change composites became two orders of magnitude larger than that of the original PCM. Metal foam with high thermal conductivity and high porosity can be applied to enhance the thermal conductivity of pure PCM. Copper foam and nickel foam with various porosities and pore sizes were impregnated with pure paraffin with vacuum assistance by Xiao et al. [9]. Their results showed that the effective thermal conductivities of the composite PCMs were drastically enhanced, e.g. the effective thermal conductivity of the paraffin/copper foam composite PCMs fabricated by the foam porosities of $88.89 \%$ and pore size of 25 PPI (pore per inch)were $16.01 \mathrm{~W} / \mathrm{m} \cdot \mathrm{K}$, which are about forty-four times larger than that of pure paraffin. In our recent work [7], we examined the thermal behavior with PCM-fin composite structure in battery thermal management and determined the characteristic temperature points. And further investigation was conducted to explore the underlying heat transfer mechanism of pure PCM along with the help of experimental visualization [10].

To avoid the risk of electrical shorting in case of the liquid leakage, different approaches have been developed to improve the safety of PCM in application. The shape-stabilized PCMs were made by the porous adsorption, microencapsulation, sol-gel method, pressing sintering, which make the PCMs avoid leaking when the phase transition occurs [11]. However, shape-stabilized PCMs made by the porous adsorption method had poor stability, made by the microencapsulation, sol-gel method and pressing sintering method had complicated preparation process. A battery thermal management system using the composite PCM was designed and developed by Wang et al. [12]. In their study, the leakage problem was solved by encapsulating composite PCM in customized aluminum boxes. 
But the aluminum boxes increases the quality of the system.

In this study, an experimental visualization prototype was also fabricated to visualize the melting process of composite PCM using both PCM and copper foam. The configuration consists of a semi-cylindrical battery allocated in the center of a semi-concentric housing made of aluminum and a transparent plate of $3 \mathrm{~mm}$ thick made of acrylics. The composite PCM was allocated into the gap among the battery, the housing and the plate. Furthermore, the leakage problem can be solved by encapsulating composite PCM into closed bags made of polyethylene (PE) film or aluminum plastic film.

\section{Experiment Methodology}

\subsection{Experimental Preparation}

The PCM used in this work was the sliced paraffin supplied by Shanghai Yiyang Instrument Co., Ltd., and its thermo-physical properties are listed in Table 1.

The mass of PCM used in the work can be estimated according to the energy conservation equation. The sensible heat and latent heat of the PCM, heat capacities of the batteries and housing and heat loss caused by natural convection all should be taken into account. Namely,

$$
\begin{aligned}
P t= & M_{\mathrm{pcm}} c_{\mathrm{pcm}}\left(T_{\max }-T_{a}\right)+\left(M_{b} c_{b}+M_{h} c_{h}\right)\left(T_{\max }-T_{a}\right) \\
& +M_{\mathrm{pcm}} \Delta H+\int_{0}^{t} h A\left(T_{\max }-T\right)_{a} \mathrm{~d} t
\end{aligned}
$$

where $P$ is the heating power (W), tis the heating time (s), $c$ is the specific heat ( $\mathrm{J} / \mathrm{kg} \cdot \mathrm{K}), M$ is the mass $(\mathrm{kg}), T_{\max } / T_{\mathrm{a}}$ is the maximum/ambient temperature $\left({ }^{\circ} \mathrm{C}\right)$, $A$ is the heat exchange area $\left(\mathrm{m}^{2}\right), h$ is the natural convective heat transfer coefficient $\left(\mathrm{W} / \mathrm{m}^{2} \cdot \mathrm{K}\right) t, \Delta H$ is the latent heat $(\mathrm{J} / \mathrm{kg})$ of PCM, and the subscript $b, h$ represent battery, housing, respectively. The copper foam with the porosity 97.5\% and pore size of 25 PPI was used in this experiment.

\subsection{Test Section}

A schematic diagram of experimental system is shown in Figure 1, which consisted of the test section with the DC power supply, the thermostat chamber, the HD camera and the data acquisition system.

As shown in Figure 1, the test section of visualization consists of a semi-cylindrical test battery in 18650 format made of aluminum allocated in the center of a semi-concentric metal housing and a transparent plate made of acrylics. The semi-cylindrical test battery was inserted with a heater to simulate the heat generation of commercial 18650 lithium-ion battery. The PCM or composite PCM was allocated into the gap among the battery, the housing and

Table 1. Thermo-physical properties of paraffin.

\begin{tabular}{ccccc}
\hline $\begin{array}{c}\text { Melting range } \\
\left({ }^{\circ} \mathrm{C}\right)\end{array}$ & $\begin{array}{c}\text { Specific heat } \\
(\mathrm{kJ} / \mathrm{kg} \cdot \mathrm{K})\end{array}$ & $\begin{array}{c}\text { Latent heat } \\
(\mathrm{kJ} / \mathrm{kg})\end{array}$ & $\begin{array}{c}\text { Thermal conductivity } \\
(\mathrm{W} / \mathrm{m} \cdot \mathrm{K})\end{array}$ & $\begin{array}{c}\text { Solid density } \\
@ 25^{\circ} \mathrm{C}\left(\mathrm{kg} \cdot \mathrm{m}^{-3}\right)\end{array}$ \\
\hline $47-53.8$ & 2 & 204.5 & 0.15 & 785 \\
\hline
\end{tabular}




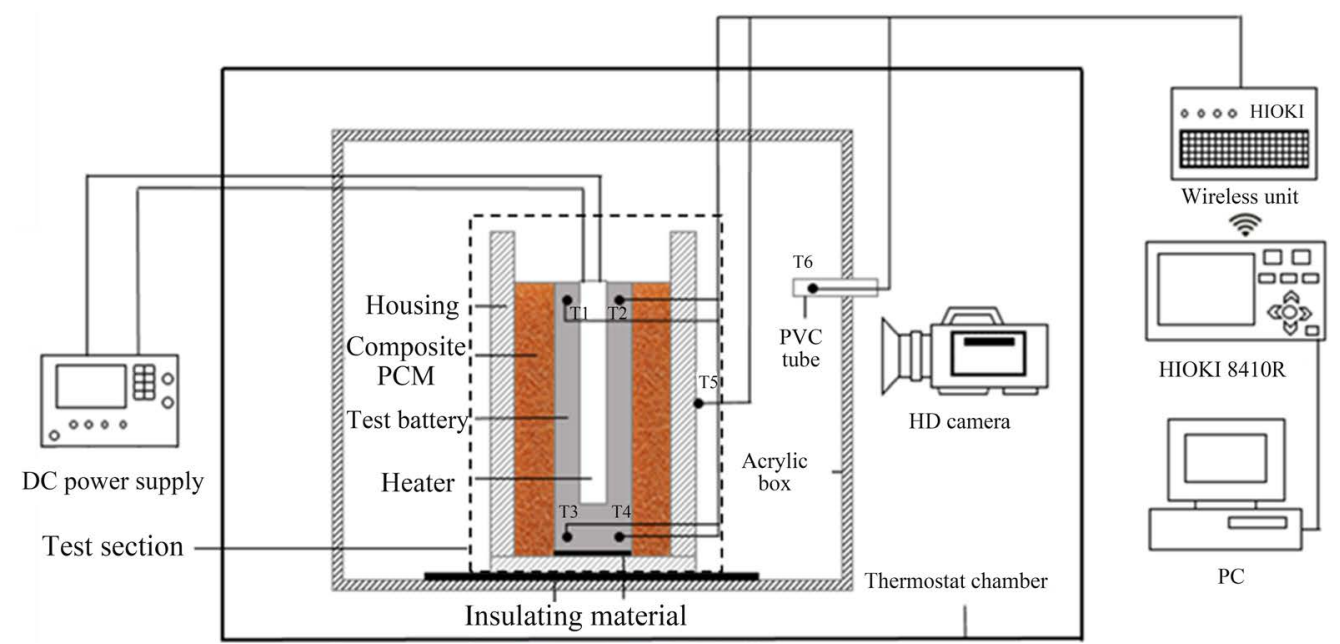

Figure 1. The schematic diagram of experimental system.

the plate. The composite PCM was allocated into the gap among the battery, the housing and the plate. The underside of the test battery was insulated from the metal housing with a layer of acrylic plate of $1 \mathrm{~mm}$. The test battery was fixed by silica gel (3145 RTV) supplied by DOW COBNING on the middle of a transparent plate with a thickness of $3 \mathrm{~mm}$ and then fixed to the housing. The test section was placed in the center of an acrylic box and insulated from the acrylic box and then placed in the thermostat chamber. The box made of acrylic plate with a thickness of $5 \mathrm{~mm}$ was to form an enclosed space to protect from ambient disturbances.

All tests in this work were conducted at an ambient temperature of $25^{\circ} \mathrm{C} \mathrm{ob}$ tained by setting the thermostat chamber. The change of heating power was achieved by changing the voltage and current of the DC power supply. The temperature of test battery was measured by the four K-type thermocouples $\left(T_{1}\right.$, $T_{2}, T_{3}, T_{4}$ ) fixed in the holes drilled at the top and bottom end surfaces, each hole $1.5 \mathrm{~mm}$ in diameter and $10 \mathrm{~mm}$ in length with its center $7.25 \mathrm{~mm}$ away from the cylinder center. And the thin aluminum foil of $0.04 \mathrm{~mm}$ thick had been tightly wrapped around the thermocouple to ensure the good thermal contact with the wall of the hole. The thermocouple $T_{5}$ was placed onto the middle of housing wall to measure the housing temperature. The ambient temperature $T_{6}$ was measured by another thermocouple inserted into PVC tube mounted inside the acrylic box. HIOKI 8410R was used for data acquisition and the thermocouple readings were recorded in $5 \mathrm{~s}$ interval, and the HD camera (Nikon D5100) was used for visual tracking of phase change process, and the DC power supply (GWINSTEK PSW110-21.6) was used to provide constant heat input for the heater.

The uncertainty analysis is given as follows. The DC power supply had a voltage resolution of $0.1 \mathrm{~V}$ and current resolution of $0.02 \mathrm{~A}$, which had a standard deviation of $0.2 \%$ in the heating power. All the K-type thermocouples used in the experiment was supplied from OMEGA, and its relative deviation was within $0.1^{\circ} \mathrm{C}$ in the calibration oven. Therefore, the uncertainty in the temperature dif- 
ference measurement was within $0.15^{\circ} \mathrm{C}$. The uncertainty of HIOKI LR8410R in the temperature data acquisition was estimated within $0.5^{\circ} \mathrm{C}$ in the absolute temperature measurement.

\section{Results and Discussions}

In this section, the experimental results are presented subsequently for the heat dissipation options including natural convection option, pure PCM option and composite cooling option with both the copper foam and PCM under the different heating power such as $6.6 \mathrm{~W}, 8.8 \mathrm{~W}$ and $13.2 \mathrm{~W}$. As discussed in this section, the experimental results of the test section are represented not only by the thermal performance, but also by the phase change process. The average temperature of four thermocouples $\left(T_{1}-T_{4}\right)$ in the test battery was used as the battery temperature $\left(T_{b}\right)$ and the thermocouple $\left(T_{5}\right)$ was identified to be the housing temperature $\left(T_{\mathrm{W}}\right)$. The test section was tested at a relatively constant room temperature of $25^{\circ} \mathrm{C}$.

\subsection{Thermal Performance of PCM and PCM/Copper Foam Options}

Experiments were carried out for the battery contained in the housing for different heat exchange conditions, natural convection, pure PCM, and composite PCM and copper foam structure. Figure 2 shows the evolutions of battery temperature for the natural convection and the pure PCM cases at different heating power. Under the natural convection option, the heat was accumulated in the battery. As a result, there is a faster battery temperature ramp-up rate in the evolution when the heating power was only $6.6 \mathrm{~W}$, which had exceeded the battery temperature ramp-up rate for pure PCM option at the heating power of $13.2 \mathrm{~W}$. To simplify Figure 2, the evolutions of battery temperature for the natural convection cases at the heating power of $8.8 \mathrm{~W}$ and $13.2 \mathrm{~W}$ are not shown in Figure 2. However, after adding PCM, the battery temperature was $50^{\circ} \mathrm{C}$ at 500 s, and the battery temperature was significantly lower than the $81.5^{\circ} \mathrm{C}$ at natural convection

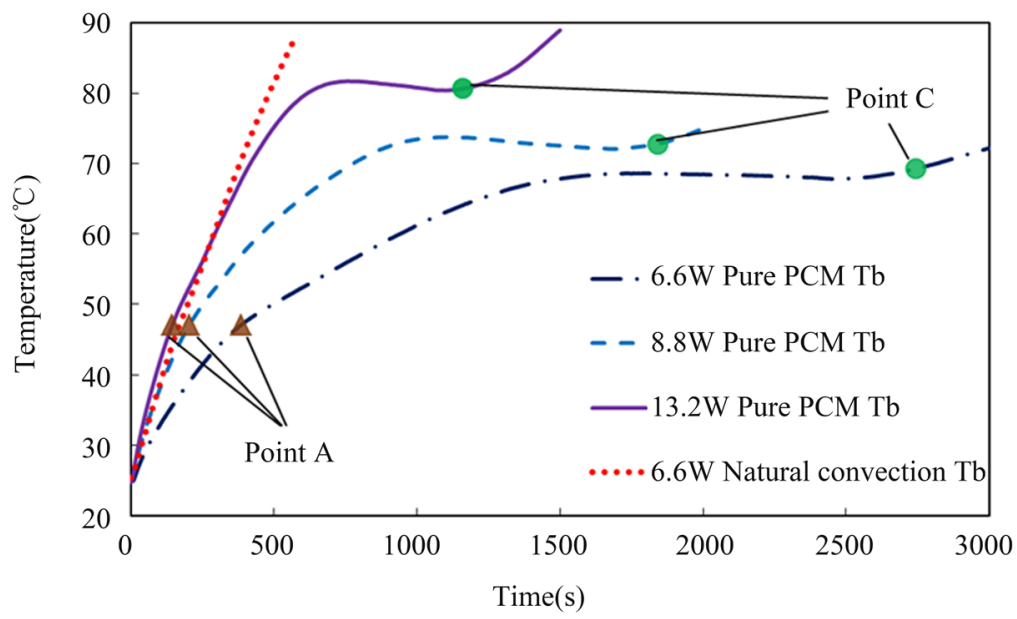

Figure 2. The evolutions of battery temperature for the natural convection and the pure PCM cases at different heating power. 
option. As shown in Figure 2, the $T_{b}$ evolutions of the pure PCM option can be divided into three distinct segments: $\mathrm{OA}$ segment, $\mathrm{AC}$ segment, $\mathrm{CE}$ segment. Here $\mathrm{O}$ and $\mathrm{E}$ are the starting point and the ending Point, respectively, not shown in Figure 2. The Point A is the melting point of PCM and the Point $\mathrm{C}$ is the effective thermal control time point. There was no phase change in the OA segments, and the heat dissipation depended on the battery heat capacity and natural convection heat loss. Therefore, OA segment exhibited high rate of temperature ramp-up. When $T_{b}$ reached the melting point of $47^{\circ} \mathrm{C}$, the PCM started to melt and absorb heat generated by the test battery, and a plateau of temperature can be clearly observed in the AC segment. Therefore, Point $\mathrm{C}$ can be regarded as the end of temperature control with PCM, beyond the Point C, the $T_{b}$ increased at an accelerated rate.

One of the key experiment tasks is to enhance the thermal conductivity of the PCM. In this work, the copper foam with the porosity $97.5 \%$ and pore size of 25 PPI was added into the PCM. The thermal performance of PCM/copper foam option was examined under the different heating power, as shown in Figure 3. For the pure PCM option, a plateau of temperature was found in the AC segment. For the finned cases, the ramp-up rates of $T_{b}$ were reduced, as indicated in Figure 3, but the temperature plateaus became less obvious. Comparing with the pure PCM option, the PCM/copper foam option could control the $T_{b}$ at a low level from the start to the end of evolutions. This can be proven that the improvement of the thermal conductivity of the PCM was obviously improved by adding the copper foam, which exceeded the adverse effect of weakening the natural convective of liquid PCM due to the addition of the copper foam.

\subsection{Phase Change Process of PCM and PCM/Copper Foam Options}

Figure 4 and Figure 5 show the evolutions of battery temperature and the phase change process for the Pure PCM and the PCM/copper foam options at the same

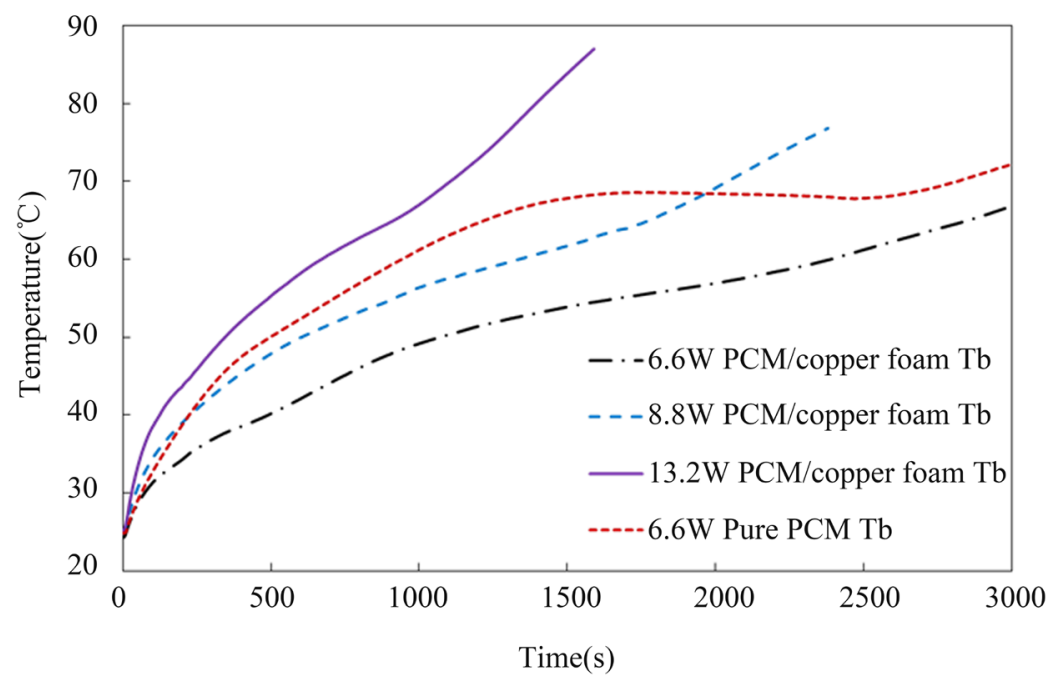

Figure 3. The evolutions of battery temperature for the pure PCM and the PCM/copper foam cases at different heating power. 


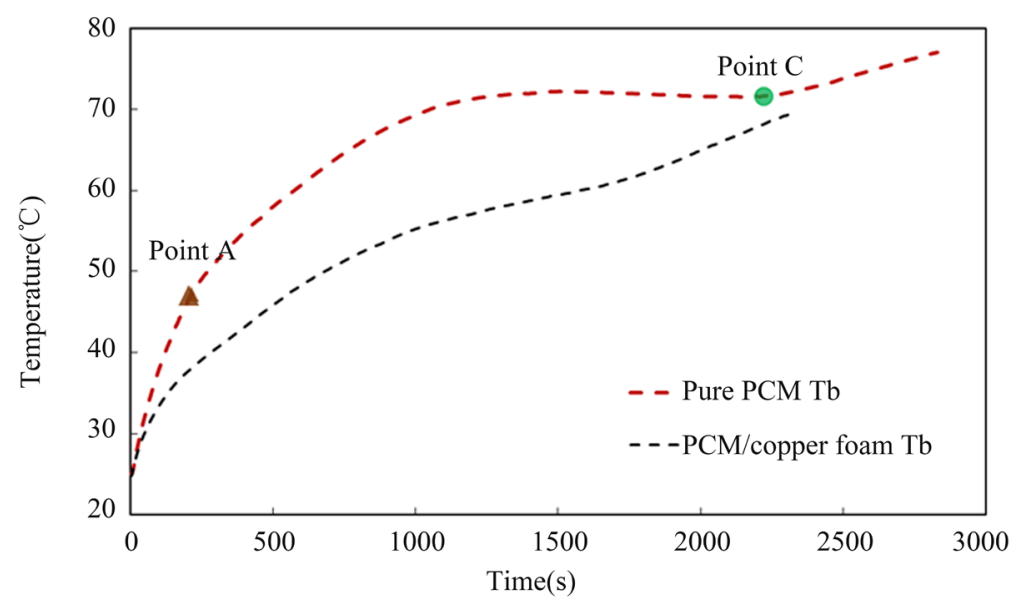

Figure 4. The evolutions of battery temperature for the Pure PCM and the PCM/copper foam options at the same heating power.

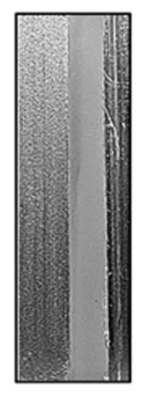

$215 \mathrm{~s}$

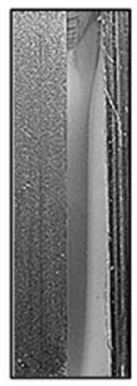

$1335 s$

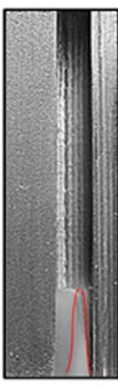

2220 s

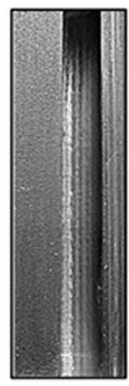

$2650 \mathrm{~s}$

(a)

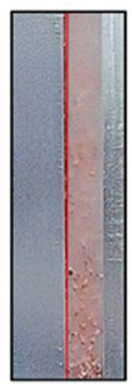

$215 \mathrm{~s}$

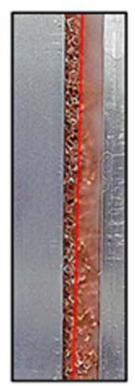

$1335 \mathrm{~s}$

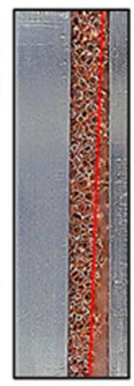

2220s 2650s

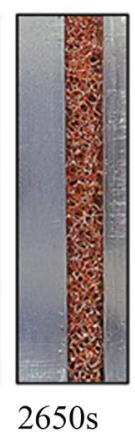

(b)

Figure 5. The evolutions of solid-liquid interface for different heat dissipation options: (a) Pure PCM; (b) PCM/copper foam.

heating power, respectively. As shown in Figure 4, the battery temperature for the PCM/copper foam options was lower that for the pure PCM option, which was same as we discussed in the 3.1 Section. Figure 5 shows the solid-liquid interface for pure PCM option and PCM/copper foam option. The left side (a) denotes the visualization experimental results for the pure PCM option and the right (b) depicts the PCM/copper foam option.

Figure 5(a) shows the evolutions of the solid-liquid phase change interface in the option of pure PCM. At the Point A, the PCM adjacent to the surface of the battery began to melt, and a drop of slope of temperature rise had appeared. As the test progressed, the natural convection of between battery and housing gradually strengthened. The solid-liquid phase change interface had been moving down along with the surface of housing, and a distinct plateau of temperature appeared in the AC section. Due to the high thermal conductivity of the aluminum housing, the PCM on the housing side melted firstly, and the unmelted PCM had a sharp peak shape. When copper foam was added, the natural convection effect was suppressed but not completely disappeared. As shown in Figure 5(b), since the natural convection was inhibited by the copper foam, the 
plateau of temperature was not obvious. But, it is worth noting that the thermal performance was better than the pure PCM option.

\subsection{The Package and Test of Composite PCM}

The copper foam was cut to the calculated size and then bent according to the radius of the battery. In this process, the copper foam should be in close contact with the surface of the battery and then put it in a bag made of PE film or aluminum plastic film. In the filling of PCM in the bag, the paraffin was first fully melted beyond the melting point in a thermostat and then poured into the bag through the opening reserved. Figure 6 was the physical model after packaging: (a) PE film, (b) aluminum plastic film.

Figure 7 shows the evolutions of battery temperature for the package PCM at

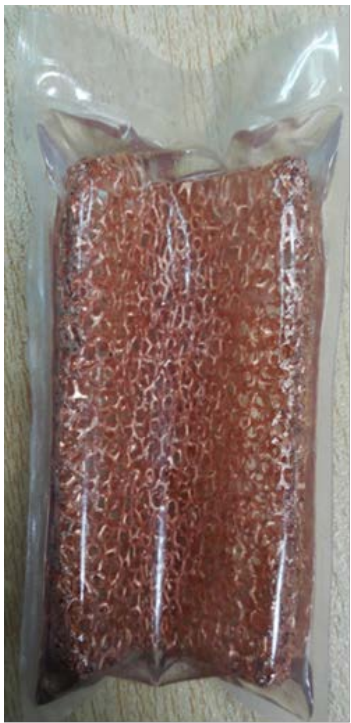

(a)

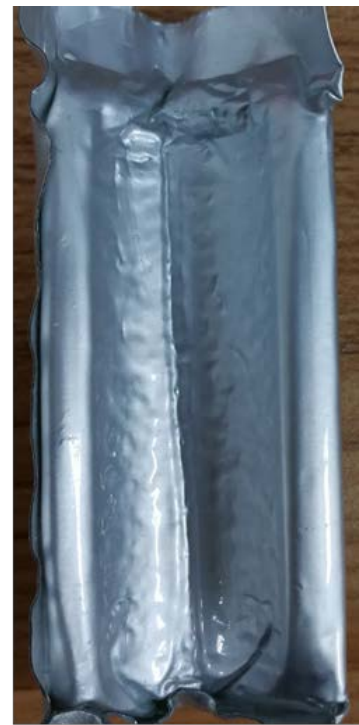

(b)

Figure 6. The physical model after packaging: (a) PE film, (b) aluminum plastic film.

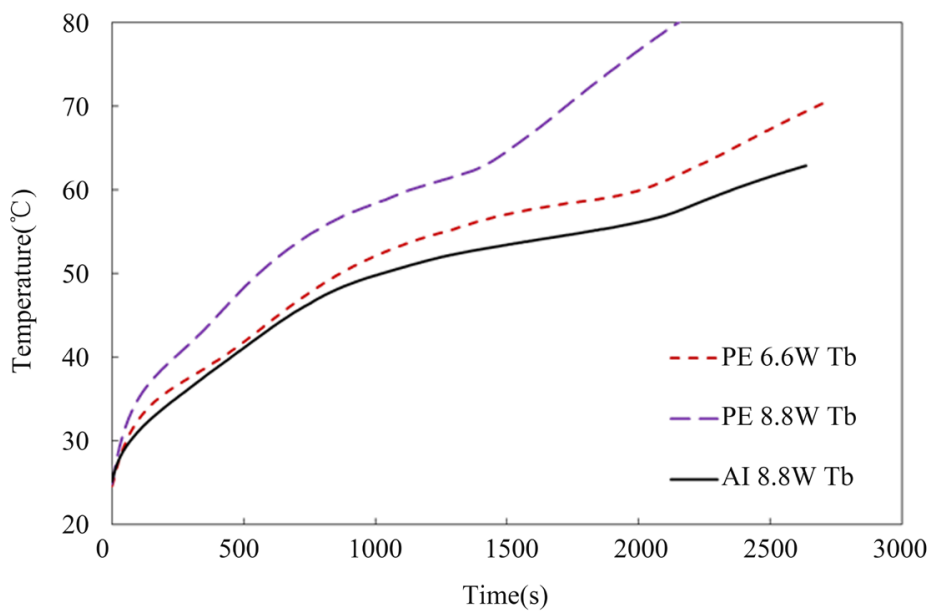

Figure 7. The evolutions of battery temperature for the package PCM at the different heating power. 
the different heating power. As shown in Figure 7, the battery temperature was increased as the increases of heating power. The battery temperature packaged by Aluminum plastic was significantly lower than packaged by PE film. This is because the aluminum plastic has a high thermal conductivity. No matter which kind of packaging materials was leaking during the test. Because aluminum film has good thermal performance and good wear resistance, we recommend using aluminum plastic film as packaging material.

\section{Conclusions}

From the experimental analysis, the main conclusions can be obtained as follows.

1) The addition of copper foam increases the thermal conductivity of PCM, which exceeded the adverse effect of weakening the natural convection of liquid PCM due to the addition of the copper foam.

2) The visualization of phase change process of phase change material (PCM) for thermal management of 18650 lithium-ion battery was studied by experimental method. The results show that the composite PCM/copper foam has better thermal performance.

3) No matter which kind of packaging materials including PE film and aluminum plastic film was leaking during the test, because aluminum film has good thermal performance and good wear resistance, we recommend using aluminum plastic film as packaging material.

\section{Acknowledgements}

Financial supports from NSTC (51876113) and STCSM (14520501100) projects are acknowledged.

\section{Conflicts of Interest}

The author declares no conflicts of interest regarding the publication of this paper.

\section{References}

[1] Putra, N., Ariantara, B. and Pamungkas, R.A. (2016) Experimental Investigation on Performance of Lithium-Ion Battery Thermal Management System Using Flat Plate Loop Heat Pipe for Electric Vehicle Application. Applied Thermal Engineering, 99, 784-789. https://doi.org/10.1016/j.applthermaleng.2016.01.123

[2] Ramadass, P., Haran, B., White, R., et al. (2002) Capacity Fade of Sony 18650 Cells Cycled at Elevated Temperatures: Part II. Capacity Fade Analysis. Journal of Power Sources, 112, 614-620. https://doi.org/10.1016/S0378-7753(02)00473-1

[3] Ping, P., Wang, Q., Huang, P., et al. (2014) Thermal Behaviour Analysis of Lithium-Ion Battery at Elevated Temperature Using Deconvolution Method. Applied Energy, 129, 261-273. https://doi.org/10.1016/j.apenergy.2014.04.092

[4] Lv, Y., Yang, X., Li, X., et al. (2016) Experimental Study on a Novel Battery Thermal Management Technology Based on Low Density Polyethylene-Enhanced Composite 
Phase Change Materials Coupled with Low Fins. Applied Energy, 178, 376-382. https://doi.org/10.1016/j.apenergy.2016.06.058

[5] Jiang, G., Huang, J., Liu, M., et al. (2017) Experiment and Simulation of Thermal Management for a Tube-Shell Li-Ion Battery Pack with Composite Phase Change Material. Applied Thermal Engineering, 120, 1-9. https://doi.org/10.1016/j.applthermaleng.2017.03.107

[6] Zhang, Z. and He, X. (2017) Three-Dimensional Numerical Study on Solid-Liquid Phase Change within Open-Celled Aluminum Foam with Porosity Gradient. Applied Thermal Engineering, 113, 298-308. https://doi.org/10.1016/j.applthermaleng.2016.10.173

[7] Wang, Z., Zhang, H. and Xia, X. (2017) Experimental Investigation on the Thermal Behavior of Cylindrical Battery with Composite Paraffin and Fin Structure. International Journal of Heat \& Mass Transfer, 109, 958-970. https://doi.org/10.1016/j.ijheatmasstransfer.2017.02.057

[8] Lazrak, A., Fourmigué, J.F. and Robin, J.F. (2017) An Innovative Practical Battery Thermal Management System Based on Phase Change Materials: Numerical and Experimental Investigations. Applied Thermal Engineering, 128, 20-32. https://doi.org/10.1016/j.applthermaleng.2017.08.172

[9] Xiao, X., Zhang, P. and Li, M. (2014) Effective Thermal Conductivity of Open-Cell Metal Foams Impregnated with Pure Paraffin for Latent Heat Storage. International Journal of Thermal Sciences, 81, 94-105. https://doi.org/10.1016/j.ijthermalsci.2014.03.006

[10] Yang, H., Zhang, H., Sui, Y., et al. (2018) Numerical Analysis and Experimental Visualization of Phase Change Material Melting Process for Thermal Management of Cylindrical Power Battery. Applied Thermal Engineering, 128, 489-499. https://doi.org/10.1016/j.applthermaleng.2017.09.022

[11] Shi, T., Fang, Y. and Zhang, H. (2015) Review on Shaped-Phase Change Material. Materials Review, S2, 437-439.

[12] Wang, W., Zhang, X., Xin, C., et al. (2018) An Experimental Study on Thermal Management of Lithium Ion Battery Packs Using an Improved Passive Method. Applied Thermal Engineering, 134, 163-170. https://doi.org/10.1016/j.applthermaleng.2018.02.011 